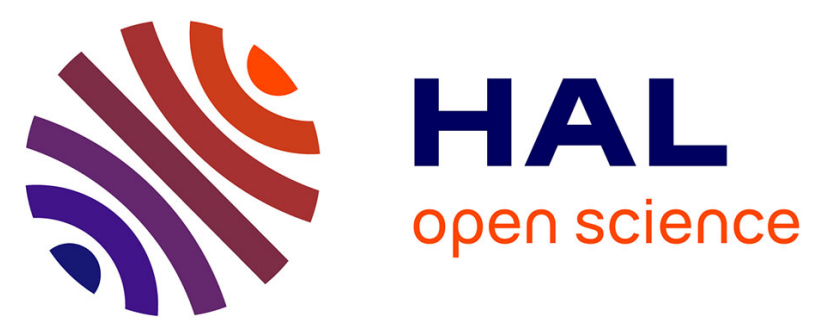

\title{
The influence of geographical access to health care and material deprivation on colorectal cancer survival: Evidence from France and England
}

O. Dejardin, A.P. Jones, B. Rachet, E. Morris, Véronique Bouvier, V. Jooste, E. Coombes, D. Forman, A.M. Bouvier, Guy Launoy

\section{To cite this version:}

O. Dejardin, A.P. Jones, B. Rachet, E. Morris, Véronique Bouvier, et al.. The influence of geographical access to health care and material deprivation on colorectal cancer survival: Evidence from France and England. Health \& Place, 2014, 30, pp.36 - 44. 10.1016/j.healthplace.2014.08.002 . inserm-01870353

\section{HAL Id: inserm-01870353 https://www.hal.inserm.fr/inserm-01870353}

Submitted on 7 Sep 2018

HAL is a multi-disciplinary open access archive for the deposit and dissemination of scientific research documents, whether they are published or not. The documents may come from teaching and research institutions in France or abroad, or from public or private research centers.
L'archive ouverte pluridisciplinaire HAL, est destinée au dépôt et à la diffusion de documents scientifiques de niveau recherche, publiés ou non, émanant des établissements d'enseignement et de recherche français ou étrangers, des laboratoires publics ou privés. 
The influence of geographical access to health care and material deprivation on colorectal cancer survival: Evidence from France and England.

$\underline{\text { Authors }}$

Dejardin $\mathrm{O}^{1}$, Jones $\mathrm{AP}^{5}$; Rachet $\mathrm{B}^{2}$, Morris $\mathrm{E}^{4}$, Bouvier $\mathrm{V}^{1}$, Jooste $\mathrm{V}^{3}$, Coombes $\mathrm{E}^{5}$, Forman $\mathrm{D}^{4,6}$, Bouvier $\mathrm{AM}^{3}$, Launoy $\mathrm{G}^{1}$

Author's affiliation

1- University Hospital of Caen ,U1086 INSERM UCBN« Cancers \& preventions », France

2- London School of Hygiene and Tropical Medicine LSHTM, Cancer Survival Group, London UK

3- Digestive Cancer Registry of Burgundy; CHU Dijon; INSERM, U866, Dijon, F21079, France; Univ Bourgogne, Dijon, F-21079, France.

4- $\quad$ Leeds Institute of Cancer \& Pathology, University of Leeds, UK

5- $\quad$ Norwich Medical School, University of East Anglia, Norwich, UK

6- International Agency for Research on Cancer (IARC), Cancer information, Lyon France

Corresponding author

Dejardin Olivier, Pôle de Recherche CHU Caen; Centre François Baclesse; Avenue du General Harris - BP 5026; 14076 Caen Cedex 05; France

Tel +33(0)231458623

Fax $+33(0) 231530852$

Mail: olivier.dejardin@unicaen.fr

Word count: 2856

Keywords: Health care accessibility; survival; travel times; colorectal cancer; France; England; material deprivation 


\section{Summary (174 words)}

This article investigates the influence of distance to health care and material deprivation on cancer survival for patients diagnosed with a colorectal cancer between 1997 and 2004 in France and England. This population-based study included all cases of colorectal cancer diagnosed between 1997 and 2004 in 3 cancer registries in France and 1 cancer registry in England ( $N=40613$ ).

After adjustment for material deprivation, travel times in England were no longer significantly associated with survival. In France patients living between 20 and 90 minutes from the nearest cancer unit tended to have a poorer survival, although this was not statistically significant.

In England, the better prognosis observed for remote patients can be explained by associations with material deprivation; distance to health services alone did not affect survival whilst material deprivation level had a major influence, with lower survival for patients living in deprived areas. Increases in travel times to health services in France were associated with poorer survival rates. The pattern of this influence seems to follow an inverse $U$ distribution, i.e. maximal for average travel times. 


\section{Introduction}

Colorectal cancer survival differs notably between France and England. The EUROCARE 4 study estimated the age-adjusted 5-year survival at 51.8\% in England and 59.9\% in France for patients diagnosed with a colorectal cancer in 2000-02 (Verdecchia et al., 2007). The reasons behind lower survival in England are not well known, but potential explanations include the higher number of deaths in older patients, higher co-morbidity prevalences and differences in management (Dejardin et al., 2013).

Large inequalities in cancer survival have been consistently identified in relation to socioeconomic deprivation in both France (Dejardin et al., 2006) and England (Coleman et al., 2004; Woods, Rachet, \& Coleman, 2006). Indeed it has been estimated that a reduction in social inequalities in cancer survival in England could prevent more than 7,000 cancer deaths in England annually (Ellis, Coleman, \& Rachet, 2012). Although later stage at diagnosis amongst more deprived patients in both countries may represent one potentially attractive explanation for the disparities observed, the observed deprivation gap in survival may also be associated with drivers such as suboptimal treatment provision, patient lifestyles, and other factors associated with the provision of health care services (Woods et al., 2006).

In response to research evidence indicating a relationship between material deprivation and cancer survival, considerable efforts have been made to tackle deprivation related inequalities in survival (Mackenbach, Bakker, \& European Network Interventions, 2003).

For example, National cancer plans, the first of which was published in 2000 in England and 2002 in France, include some specific components relating to material deprivation and cancer control and prevention efforts. These include multidisciplinary team meetings for all patients, efforts to ensure early detection in all population groups, funds for research interventions dedicated to tackle social disparities in France around use of patient navigator programmes, and efforts for early detection, screening and optimal treatment in England such as actions to encourage smoking cessation in 
deprived areas, to encourage walking and cycling, particularly in deprived areas, and funding opportunities to develop palliative care for socially deprived groups.

Geographical inequalities are known to vary according to the type of health care organization. For example, in Scotland, a longer distance to hospital was associated with a higher probability of being diagnosed with colorectal cancer at time of death (Campbell et al., 2000) but was not significantly associated with survival in either Scotland or the North of England (Jones et al., 2008b). Yet research in others settings has shown strong associations with survival, including studies from France (Dejardin et al., 2008), the United-States (US) (Henry, Niu, \& Boscoe, 2009; L. Huang, Pickle, Stinchcomb, \& Feuer, 2007) and Australia (Baade, Dasgupta, Aitken, \& Turrell, 2011).

The putative mechanisms of how geographical factors impact cancer survival are complex and multi-dimensional (Meilleur et al., 2013). One potential explanation is the effect of travel times on patients' likelihood to seek care, and the consequent impact of this on stage at diagnosis. However, this relationship is unclear, since some publications report an association (Campbell et al., 2001; B. Huang, Dignan, Han, \& Johnson, 2009) whilst others do not (Haynes, Pearce, \& Barnett, 2008; Henry et al., 2013; Koka, Potti, Fraiman, Hanekom, \& Hanley, 2002). Some publications have also reported that patients living far from treatments centres receive sub-optimal treatments (Crawford et al., 2009; Dejardin et al., 2008), although such findings are not universal (Campbell et al., 2002; Jones et al., 2008a). Another potential factor is specific to the French health care system, which is based on patients being able to choose freely the hospital they wish to go to. Whilst this means that all patients theoretically have access to specialized care, free hospital choice combined with high preference for proximity (Bouche, Migeot, Mathoulin-Pelissier, Salamon, \& Ingrand, 2008) could mean that some patients miss out on the best possible treatment.

Population-based cancer registries offer an attractive way to investigate the effect of geographical differences in access to health care on cancer outcomes. Since the influence of such geographical inequalities may be partially mediated by the stage at diagnosis, it is crucial to control 
for stage at diagnosis. Population-based cancer registries also ensure the completeness of cases in the study areas.

The aim of this article was to investigate the influence of distance to health care and material deprivation on cancer survival for patients diagnosed with a colorectal cancer between 1997 and 2004 in France and England. 


\section{Materials \& methods}

\section{Population}

. This study included all cases of colorectal cancer (C18.0 to C20.9) (ICDO-3) (Fritz et al., 2000) diagnosed between 1997 and 2004 (follow-up to 31/12/2007) in 3 cancer registries in France (Calvados, Côte d'Or and Saone et Loire, 3\% the whole national population) and 1 cancer registry in England (Northern and Yorkshire Region), which covers 13.3\% of England ( $\mathrm{N}=40613$ ) (Table 1). Patients with secondary cancer and patients under 15 years old were excluded. The methods of this study have been previously published elsewhere (Dejardin et al., 2013)

\section{Variables}

Age, sex and cancer site (ICDO-3) (Fritz et al., 2000) were collected by the cancer registries. Survival time was defined as difference between and date of diagnosis and date of last contact for vital status. Only $2.38 \%$ of patients were lost to follow-up in France (end of follow-up 31/1/2008), with none lost in England. The number of zero-day survival patients was 18 in France and 946 in England (included in survival analysis with 1 day survival). Stage was coded using Duke's classification: Duke's A: Limited to mucosa; Duke's B: Penetrating through muscularis propria; Duke's C: lymph nodes involved; “Duke's D”: a least one metastasis.

Cancer registry records were integrated with geographical measures of population material deprivation based on the location of patients at time of diagnosis. The geographical units used were Lower Super Output Areas (LSOA) in England (min population 296/max population 14689; mean population 1620; http://www.ons.gov.uk/ ) and "Ilôt Regroupé pour l'Information Statistique" (IRIS) units in France (min population $0^{1} /$ max population 9618; mean population 2000;

\section{http://www.insee.fr/fr/methodes).}

To examine the association between survival and area deprivation, the Townsend index of material deprivation was computed for each IRIS in France and each LSOA in England. The Townsend

\footnotetext{
${ }^{1}$ Six communes (=IRIS) were designated as "dead for France" during the WW1.
} 
index scores are generated from census based measures of unemployment (as a percentage of those aged 16 and over who are economically active); non-car ownership (as a percentage of all households); non-home ownership (as a percentage of all households); and household overcrowding. To assist with comparison across the two countries, this index was analysed by using categories based on national quintiles.

Three different measures of travel-times were used. These were travel time between the residential location of patients at time of diagnosis and the nearest cancer centre, the nearest hospital, and the nearest radiotherapy unit. These travel times were estimated using a Geographical Information System (ArcGIS in England and MAPINFO for France) combined with a road-map database (Multinet TéléAtlas for France and Ordnance Survey Meridian data in England). Travel speeds, computed in minutes, were estimated according to legal speeds for the different road classes.

Travel times to the nearest hospital include only those hospitals that had a colorectal cancer team. These were selected as they have previously been investigated in international publications and should be considered as measure of potential access to health care (Campbell et al., 2000; Dejardin et al., 2008; Jones et al., 2008b). For the purposes of analysis, travel time was categorized based on 5 categories $(0-5 ; 6-20 ; 21-40 ; 41-90 ;+91$ for travel time to the nearest cancer centre and travel time to the nearest radiotherapy unit and $0-5 ; 6-10 ; 11-15 ; 16-40 ;+41$ for travel time to the nearest hospital). Categories were defined by using knots (four knots) of restricted cubic splines (mkspline and xblc stata command).

\section{Statistical analysis}

To examine associations between material deprivation, access and cancer survival in the two countries, multivariate excess hazard models based on a generalized linear model with Poisson error (Dickman, Sloggett, Hills, \& Hakulinen, 2004) were used. Such models estimate the excess hazard of 
death experienced by the cancer patients, i.e. the mortality hazard in excess to the mortality hazard observed in the general population with similar characteristics ('background or expected hazard'). Background hazard of death is provided by life tables. Causes of death are not available in French or English registries. In the absence of this information, cancer survival is commonly estimated by a relative survival approach that removes from the observed all-cause mortality the expected 'background' mortality. Background mortality was provided by life tables stratified according to age, sex, year of diagnosis and administrative area. This method is preferable to one based on actual cause of death as a recent publication shows that specific survival is a biased estimator of net survival due to the process of censoring of information(Danieli, Remontet, Bossard, Roche, \& Belot, 2012). Since material deprivation-specific life tables were not available in France, the life tables used in this study were stratified on age, sex, year of diagnosis, area of residence (Administrative D epartment in France and Government Office Region in England). General mortality life table are not available at a smallest geographical level. Excess Hazard Ratios (EHR) are interpreted as the relative risk of death from cancer associated with a given factor. Time since diagnosis was split as follows: 0-3 months; 3-6 months; 6 months-1 year; $1-2$ years; $2-3$ years; $3-4$ years; $4-5$ years. Interactions were tested using a likelihood ratio test. All analyses were computed by using STATA 12.1 (StataCorp. 2011. Stata: Release 12. Statistical Software. College Station, TX: StataCorp LP) software using a publicly available procedure (Estimating and modelling relative survival, available at http://www.pauldickman.com/).

To investigate the influence of remoteness and material deprivation on colorectal cancer survival in France and England, the multivariate excess hazard model included both countries with interactions ( material deprivation and countries; travel times and countries) (results not presented). For multivariate analysis, travel times were modelled as being mutually exclusive, whereby only one of the selected measures of remoteness was included in each model. Tests for linear-trend across categories were estimated by modelling including the ordered variable as continuous.

Unknown cases of variables containing missing values presented in table 1 (stage at diagnosis, cancer localization, Townsend deprivation index and travel times), were imputed using multiple 
imputations by chained equations (Little \& Rubin, 2002). The imputation model included all variables used in the analytical models (survival time, vital status, age, sex, topography, stage, year of diagnosis, material deprivation and travel times), as has been recommended (Nur, Shack, Rachet, Carpenter, \& Coleman, 2010). The imputation model was stratified according to country as the missingness mechanism might differ. Iterations were conducted to create 20 completed datasets, and the estimates were combined according to the Rubin rules (Rubin, 1987). Multiple imputation models were conducted by using conjointly the STATA 12.1 module for imputation (StataCorp. 2011. Stata: Release 12. Statistical Software. College Station, TX: StataCorp LP) and the user-written Stata command ice (Royston, 2009). Since there was a large number of missing values for stage, we also reported results by using complete case analysis, as recommended by guidelines on missing data in epidemiological and clinical research (Sterne et al., 2009). In this framework, restricted cubic splines were used to investigate the influence of travel times to the nearest cancer centre on excess hazard ratio. 


\section{Results}

The travel time to the nearest cancer centre was significantly greater in France than in England (Figure 1), with a mean of 49.57 minutes ( $95 \% \mathrm{Cl} 48.80$ - 50.34 minutes) in France compared to 32.87 minutes (32.57 - 33.17 minutes) in England (online S1).

\section{Survival analysis}

There was a significant interaction between country of residence and material deprivation $(p<0.004)$ and between country of residence and travel time to the nearest cancer centre $(p=0.007)$ (results not presented). Therefore, subsequent results were stratified according to country. Interactions between material deprivation and time since diagnosis were not statistically significant.

Figure 1: Distribution of travel time to nearest cancer unit according to material deprivation quintile in France and England

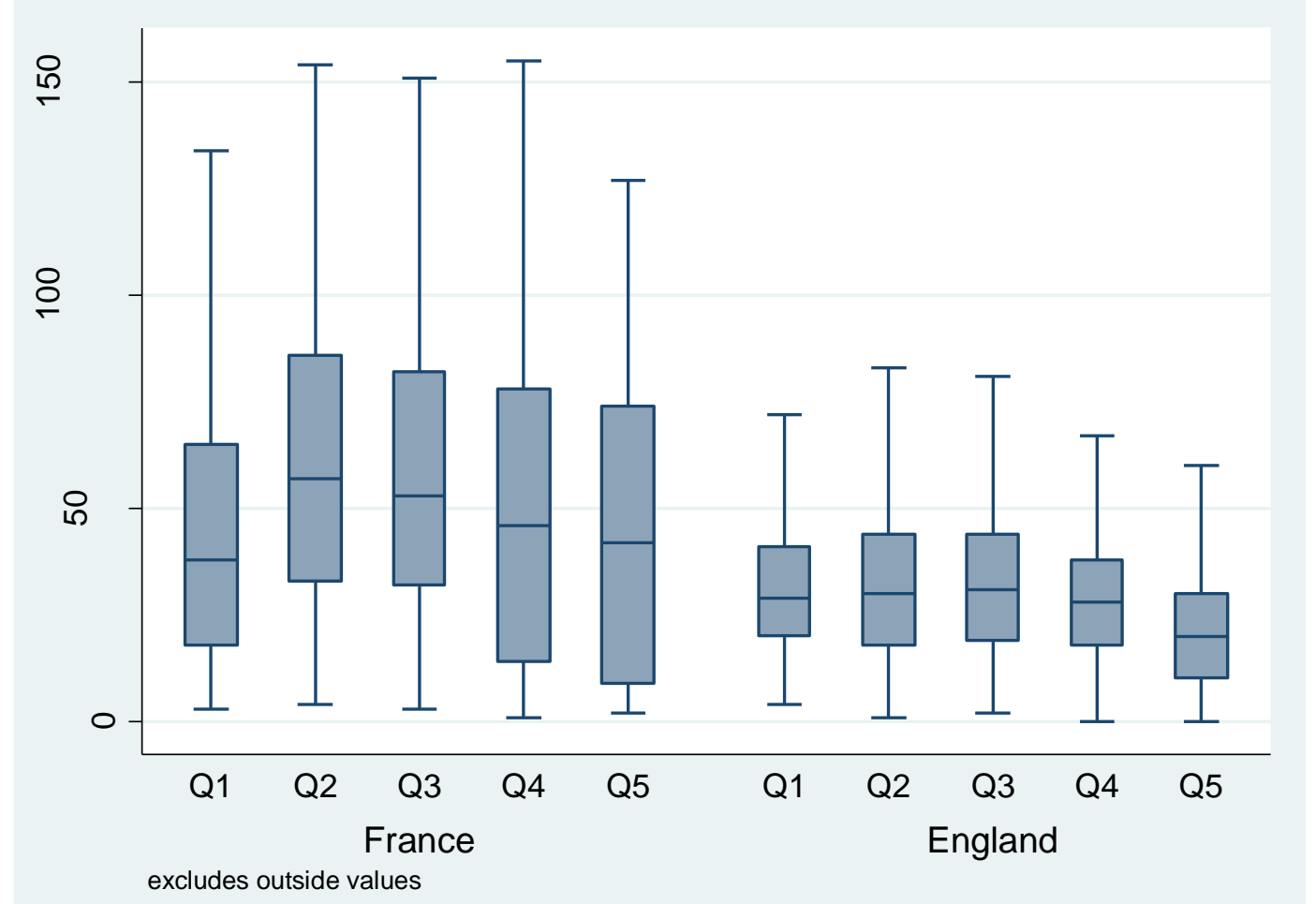


Townsend index scores were significantly associated with survival $(p<0.001)$, whereby patients living in less deprived areas had better survival than those living in underprivileged areas. Compared to material deprivation 1 (least deprived), unadjusted EHR increased from 1.13 (1.06-1.21) for material deprivation 2 up to 1.55 (1.46-1.66) for material deprivation 5 (most deprived) (Figure 2, model 1). In unadjusted analyses, travel times were significantly associated with survival, whereby patients living further from health care resources had a better survival than those living closer (respectively, EHR= $0.86(0.76-0.96) ; 0.86(0.77-0.97) ; 0.83(0.73-0.94)$ and $0.81(0.70-0.90)$ for categories 2; 3; 4 and 5 compared to category 1) (Figure 2, model 1).

Figure2: Effect of travel times and material deprivation on colorectal cancer survival for patients diagnosed between 1997 and 2004 in England.

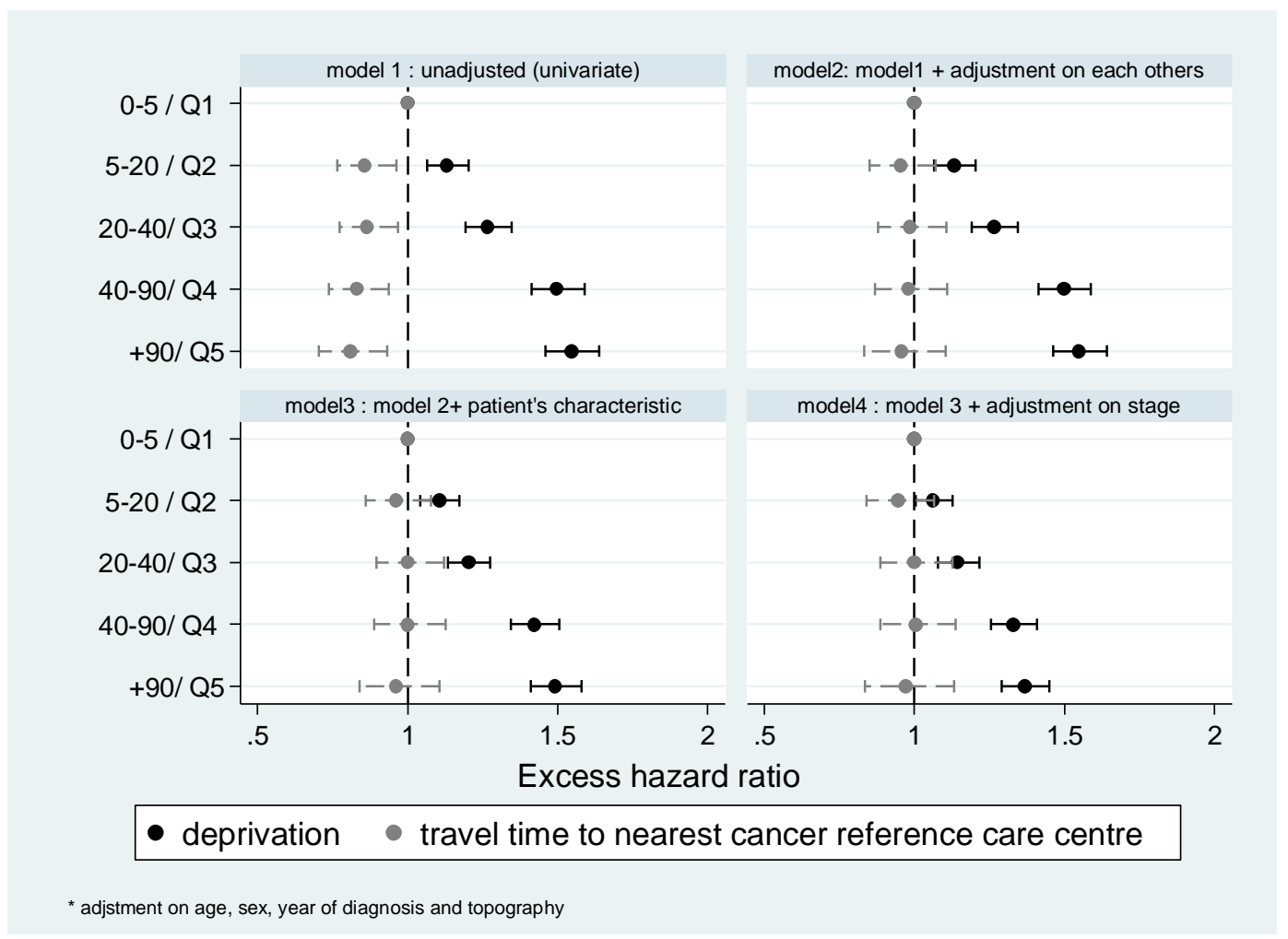

After adjustment for material deprivation, travel times were no longer significantly associated with survival, and patients living further from health care resources had a comparable survival to 
those living closer (Figure 2, model 2). Successive adjustment for age, year of diagnosis, sex and cancer localisation did not affect the association between material deprivation and geographical variables and survival (Figure 2, model 3). After taking into account stage at diagnosis, the influence of the Townsend index decreased but was still highly significant ( $p$-trend $<0.001$ ), whilst travel times remained not significantly associated with excess hazard of death (Table 2). Other travel times were not associated with survival (Figure 3).

\section{Influence of material deprivation and travel time on survival for patients diagnosed in France}

Material deprivation index scores were significantly associated with survival $(p<0.001)$, whereby patients living in the less deprived areas had a better survival than those living in the most disadvantaged areas (EHR= 1.19 (1.05-1.34) for quintile 5 compared to quintile 1) (Figure 3, model 1). In the unadjusted analysis, travel time to the nearest cancer unit was not significantly associated with survival (Figure 3, model 1). 
Figure3: Effect of travel times and material deprivation on colorectal cancer survival for patients diagnosed between 1997 and 2004 in France.

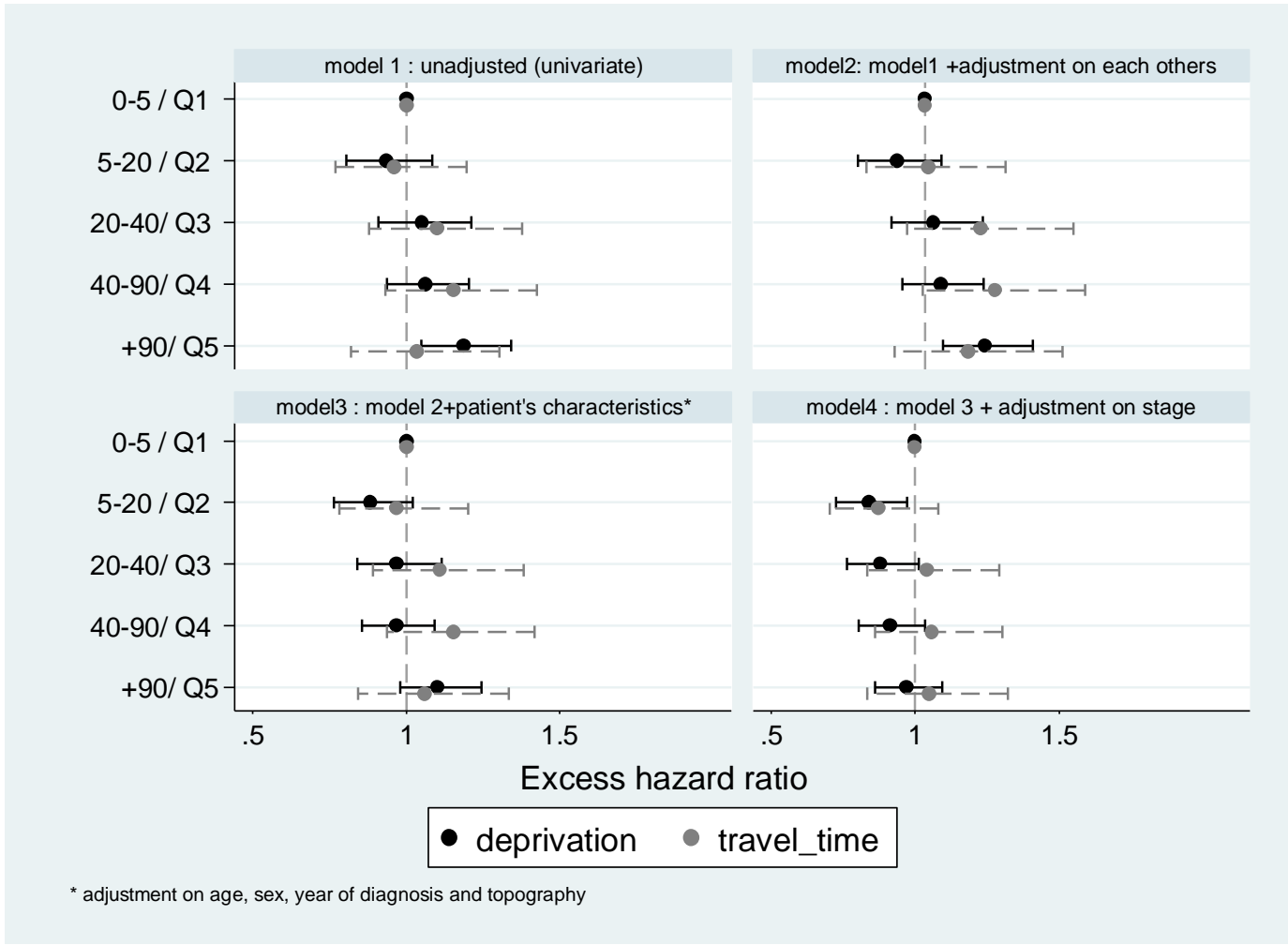

After adjustment for material deprivation, travel time to the nearest cancer unit remained not significantly associated with survival. Nonetheless, even though the association was not statistically significant, patients living between 20 and 90 minutes from the nearest cancer unit tended to have a poorer survival (Figure2, model 2). Patients living further from health care resources had a worse survival than those living closer (Table2, model 2). After adjustment for age, sex, year of diagnosis and localisation, the association remained unchanged (Figure 3, model 3). After further adjustment for stage at diagnosis, material deprivation was no longer significantly associated with survival, although the strength of the association with travel times to health care resources decreased (Table 2). With similar adjustment, survival was poorer for patients living between 5 and 40 minutes travel time from the nearest hospital and for patients with longer travel times to the nearest radiotherapy centre (Figure 4). 
Figure 4: Effect of travel times on colorectal cancer survival according to country of residence after adjustment on age, sex, year of diagnosis, topography, stage and material deprivation.

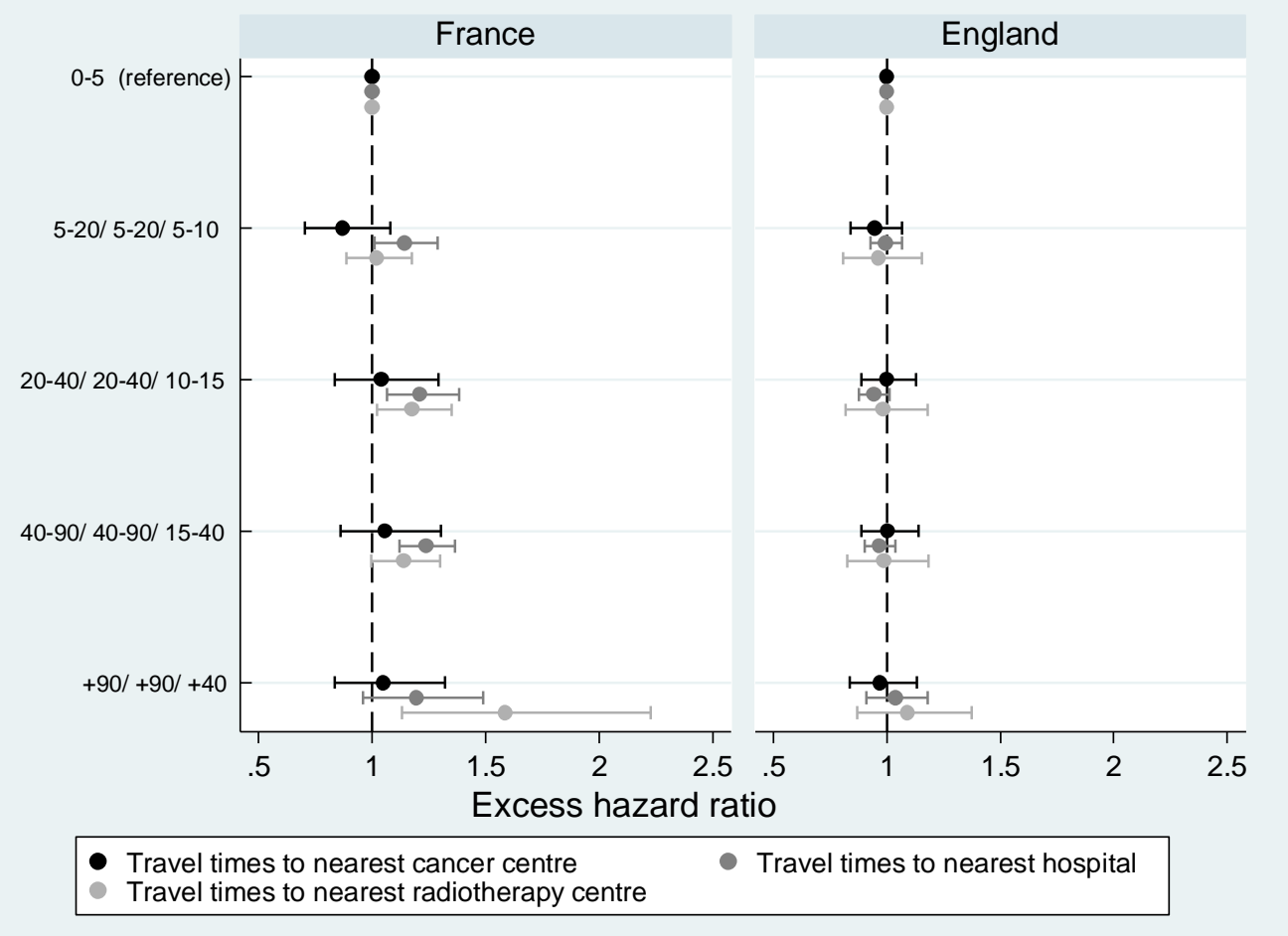

\section{Complete case analysis results}

For the complete case analysis, all associations between socioeconomic and geographical variables and survival or stage at diagnosis were consistent with those previously highlighted with multiple imputations. Moreover, travel time to the nearest cancer centre was associated with survival, following an inverse $U$ distribution (Figure 5). In light of this inverse $U$ distribution, we investigated the characteristic of these middle travel time patients. Such patients were comparable to the rest of the sample in terms of age, sex, year of diagnosis and stage at diagnosis (results not presented). 
Figure 5: Effect of travel-times to nearest reference care centre on Excess hazard ratio by country

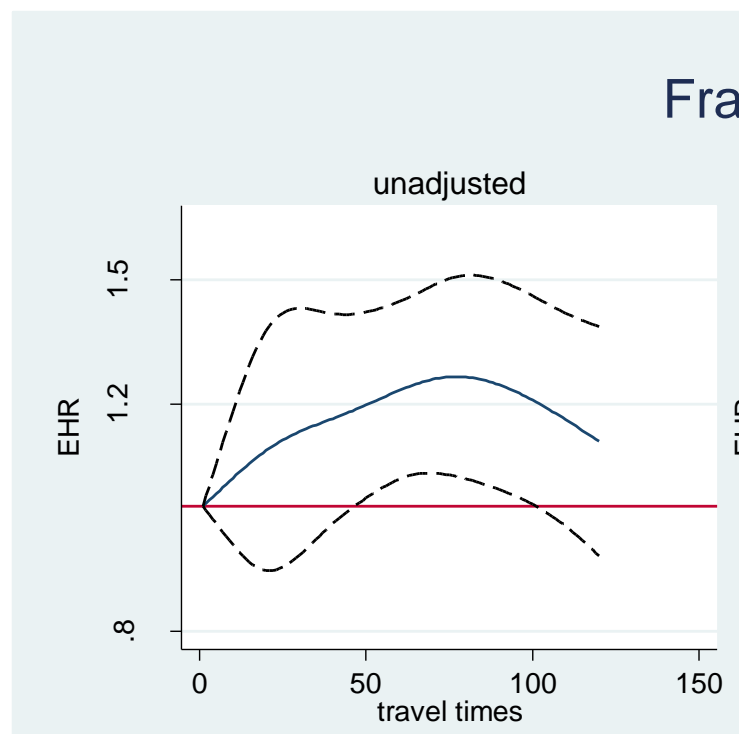

\section{France}

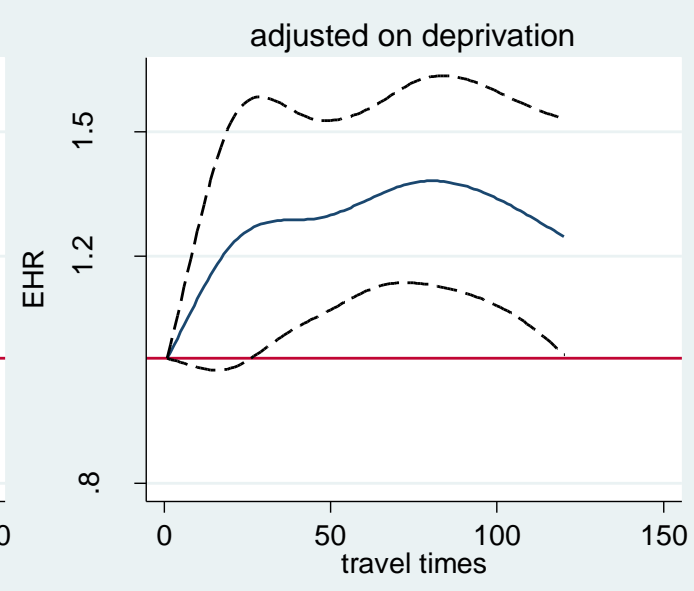

\section{England}
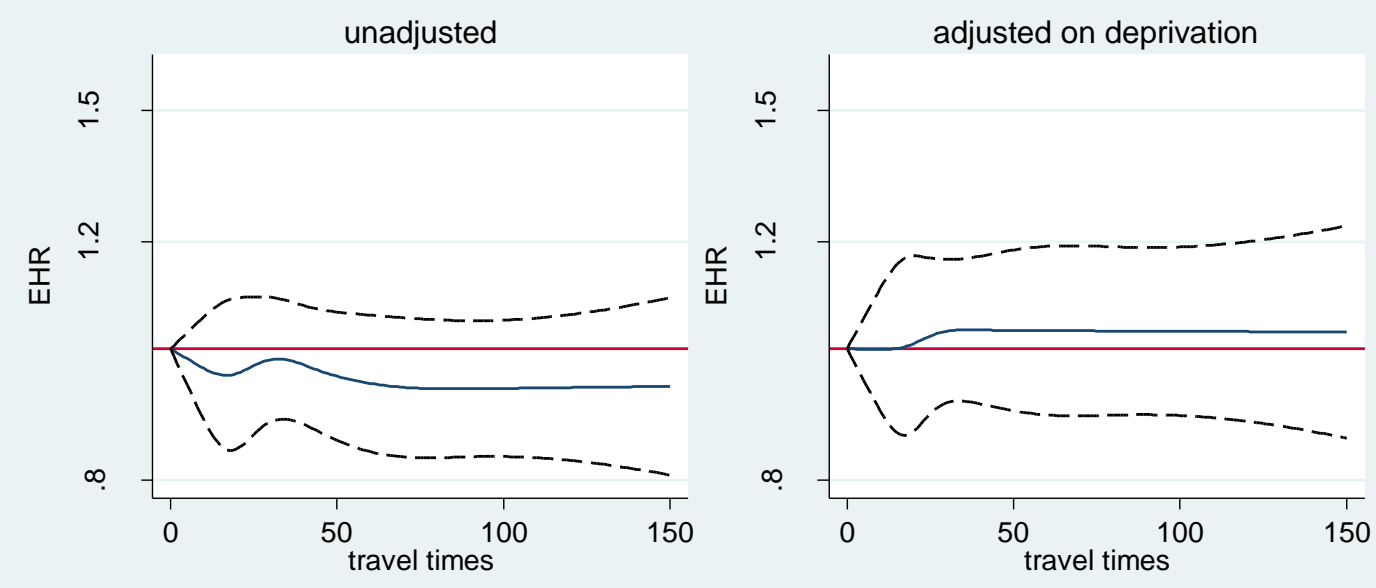

EHR ------- Lower 95Cl\% ------- Upper 95C1\%

Note: Since, travel time is a continuous variable; this graph represents the effect of an increase of one minute travel time on the Excess Hazard ratio 


\section{Discussion}

Our study shows that the survival of individuals with colorectal cancer differs according to both material deprivation and distance from healthcare services, but the effects were not the same in England and France. In England, the better prognosis observed for remote patients can be explained by a correlation with material deprivation; distance to health services alone did not affect survival whilst material deprivation level had a major influence, with lower survival for patients living in deprived areas. Even though the finding was not statistically significant, increases in travel times to health services in France were found to be associated with reductions in survival rates. The pattern of this influence seems to follow an inverse $U$ distribution, i.e. maximal for average travel times.

In France, the influence of travel-time to nearest cancer reference care centre on the excess hazard ratio is not linear but rather is represented by an inverse $U$ curve with highest excess of mortality for patients with average travel times. Comparison of available characteristics (age, sex, stage of cancer at diagnosis) of such patients with the rest of the sample showed no clear differences. We are thus not in position to explain this observation our study, although the observed trend may be due to factors associated with differences in care such as types of treatment given, the time between the different treatments, and place of treatment. Unfortunately the level of information on treatment collected by the registries is not good enough to allow us to explore these possibilities further in our study, and further work is needed.

Our results are in accordance with previous work on the influence of remoteness on French patients. A geographical gap in survival was originally identified as early as 1992 in France (Launoy, Le Coutour, Gignoux, Pottier, \& Dugleux, 1992), whereby rural colorectal patients had a worse survival than urban ones. Using road distance instead of a simple measure of rurality, this result was subsequently confirmed for digestive cancers (Dejardin et al., 2008; Dejardin et al., 2006). Despite these findings, we believe that the considerable computational demands of computing measures of 
distance or travel time in large population samples may explain the relative paucity of studies on this topic. In the UK, findings on the influence of remoteness on survival notably differ according to cancer localisations. After adjustment for stage and material deprivation, two studies reported an association between distance to the nearest cancer centre and survival in prostate cancer, although the relationship was not significant for stomach, ovary and colorectal cancers (Campbell et al., 2000; Jones et al., 2008b). Results concerning the association between survival and distance to the nearest cancer centre were not consistent across these two studies for lung and breast cancer. Nevertheless, the same authors reported that remote colorectal cancer patients had a greater probability of being diagnosed at death (DCO - Death Certificate Only) (Campbell et al., 2000; Jones, Haynes, Sauerzapf, Crawford, \& Forman, 2010). Since there is no DCO code in France, we were not in a position to investigate this issue.

This study includes only a small percentage of each country (respectively $3 \%$ of the national population of France and $13.3 \%$ of the national population of England). Concerning France, this study required information on stage at diagnosis and treatment which is only available in specialized cancer registries. The three specialized digestive cancer registries in France are located in Calvados, Côte d'Or and Saone et Loire, these areas being mainly rural, with two having a reference cancer centre (University hospital cancer care centre) in their regional capital. Nonetheless, colorectal cancer survival at one and five years in these departments is close to that estimated for the national population(Bossard et al., 2007). In England the study area was chosen to be representative of both extreme urban and rural populations, although we recognize the small relative sample size in both countries may limit the generalizability of these findings

Another limitation of this study is the lack of material deprivation-specific life tables in France. Relative survival uses general population mortality rates to estimate the expected mortality, and the lack of a material deprivation-specific life table does not allow the well-known difference in mortality according to material deprivation quintiles to be accounted for (Grafféo, Jooste, \& Giorgi, 2012). Consequently, the material deprivation gap in survival is over-estimated. Since background mortality 
differs according to rural/urban status, the same problem (absence of life table stratified on urban/rural status) occurs when estimating the influence of rural areas (and thus the influence of travel times) on relative survival. The magnitude of this bias depends on the size and the direction of inequalities in general mortality according to the variables of interest.

The geographical units used in this study were the LSOAs and IRIS areas, which were both designed for analysing small areas. Since information on the socioeconomic status of individuals is not available in cancer registries in France or in England, the use of this deprivation index is a pragmatic solution. Indeed, it is commonly argued that using area-level data is a valid and useful approach for circumventing the lack of individual information in medical files(Krieger, 1992). Deprivation indices are also a pragmatic measure since they also capture contextual effects resulting from a better social network or a better environment in least deprived areas, even if such effects cannot be distinguished from compositional effects.

The variables we examined to measure health care accessibility refer to access to hospitals. Contrary to previous studies, we were not in a position to investigate the influence of access to primary care on survival. Since geographical accessibility to primary care could be more important than access to secondary care in England (Jones et al., 2008b), this constitutes a limitation. In France, patients need to be first seen by a general practitioner but only since 2006 , i.e. after the years of incidence of this study. Another limitation is that variables for health care accessibility only concerned road distance by car. Unlike previous authors (Jones et al., 2008b), we were not in a position to compute travel times by other services like bus or train. A final limitation is that these analyses are cross-sectional in nature so we were unable to determine whether the associations we detected were causal.

Our study confirms the well-known material deprivation gap in colorectal cancer survival in England (Woods et al., 2006). Nonetheless, after adjustment for stage at diagnosis, the colorectal cancer survival in France was not affected by material deprivation. This result is in the opposite direction to that hypothesised by previous work conducted in the same French areas (Dejardin et al., 
2008). However, previous work used the Carstairs Index for deprivation, was based on crude Cox survival models, and did not take into account missing values. Overall, the material deprivation gap for colorectal cancer survival seems to be modest in France and largely explained by stage at diagnosis.

The centralization of cancer care in France to improve quality of care could be seen as a problem for patients living far from reference care centres. The reasons for the observed disparities need to be investigated in depth since spatial inequalities could represent a loss of opportunity for remote patients. The better health outcomes in high volume surgery hospitals combined with the preference of remote patients for proximity is an attractive explanation. In England, the situation is quite different. Our study shows that the presence of better health amongst rural patients is largely explained by differences in material deprivation.

\section{Acknowledgments}

The authors thank the French National cancer institute and the "Fondation de France", which provided financial support for this study. BR and EM were supported by Cancer Research UK (C1336/A5735 and C23434/A9805 respectively). 
Table 1: Patients diagnosed with colorectal cancer in the ISSUE study between 1997-2004 (N=40 613).

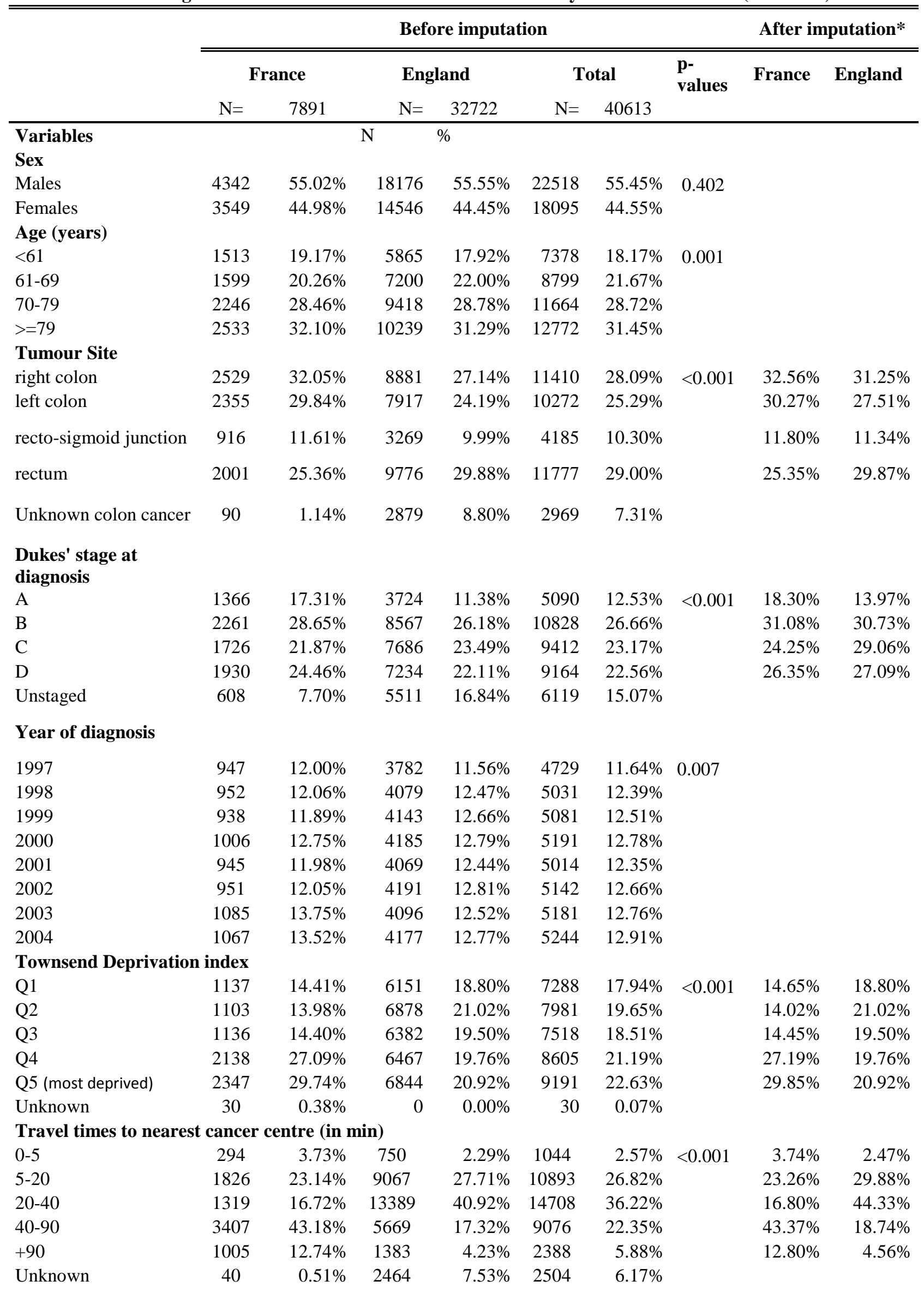


Travel times to nearest radiotherapy centre (in min)

\begin{tabular}{lcrrrrrrrr}
$0-5$ & 905 & $11.47 \%$ & 333 & $1.02 \%$ & 1238 & $3.05 \%$ & $<0.001$ & $11.52 \%$ & $1.10 \%$ \\
$5-20$ & 2217 & $28.10 \%$ & 6031 & $18.43 \%$ & 8248 & $20.31 \%$ & $28.22 \%$ & $19.83 \%$ \\
$20-40$ & 1949 & $24.70 \%$ & 13128 & $40.12 \%$ & 15077 & $37.12 \%$ & $24.82 \%$ & $43.32 \%$ \\
$40-90$ & 2675 & $33.90 \%$ & 10174 & $31.09 \%$ & 12849 & $31.64 \%$ & $34.08 \%$ & $33.79 \%$ \\
+90 & 105 & $1.33 \%$ & 592 & $1.81 \%$ & 697 & $1.72 \%$ & $1.33 \%$ & $1.95 \%$ \\
Unknown & 40 & $0.51 \%$ & 2464 & $7.53 \%$ & 2504 & $6.17 \%$ & & \\
Travel times to nearest hospital (in min) & & & & & & \\
$0-5$ & 2715 & $34.41 \%$ & 2792 & $8.53 \%$ & 5507 & $13.56 \%$ & $<0.001$ & $34.58 \%$ & $9.17 \%$ \\
$5-10$ & 1191 & $15.09 \%$ & 7861 & $24.02 \%$ & 9052 & $22.29 \%$ & & $15.16 \%$ & $25.87 \%$ \\
$10-15$ & 988 & $12.52 \%$ & 8740 & $26.71 \%$ & 9728 & $23.95 \%$ & $12.58 \%$ & $28.84 \%$ \\
$15-40$ & 2648 & $33.56 \%$ & 9752 & $29.80 \%$ & 12400 & $30.53 \%$ & $33.72 \%$ & $32.39 \%$ \\
+40 & 309 & $3.92 \%$ & 1113 & $3.40 \%$ & 1422 & $3.50 \%$ & $3.93 \%$ & $3.70 \%$ \\
Unknown & 40 & $0.51 \%$ & 2464 & $7.53 \%$ & 2504 & $6.17 \%$ & & \\
\hline \hline
\end{tabular}

* crude numbers differ according imputations ** only for variables with missing data 
Table 2: Excess Hazard ratio of death for patients diagnosed with colorectal cancer between 1997 and 2004 in France of England

\begin{tabular}{|c|c|c|c|c|c|c|c|c|}
\hline \multirow{2}{*}{ Sex } & \multicolumn{4}{|c|}{ France } & \multicolumn{4}{|c|}{ England } \\
\hline & EHR & \multicolumn{2}{|c|}{$95 \% \mathrm{Cl}$} & \multirow{3}{*}{$\begin{array}{r}\text { p-trend } \\
0,129\end{array}$} & \multirow{3}{*}{$\begin{array}{l}\text { EHR } \\
1,00\end{array}$} & \multicolumn{2}{|c|}{$95 \% \mathrm{Cl}$} & \multirow{4}{*}{$\begin{array}{r}\text { p-trend } \\
0,242\end{array}$} \\
\hline Males & & & & & & & & \\
\hline & 1,00 & & & & & & & \\
\hline Females & 0,95 & 0,88 & 1,02 & & 1,03 & 0,99 & 1,07 & \\
\hline \multicolumn{9}{|l|}{ Age } \\
\hline$<61$ & 1,000 & & & $<0,001$ & 1,00 & & & $<0,001$ \\
\hline 61-69 & 1,18 & 1,05 & 1,33 & & 1,17 & 1,11 & 1,24 & \\
\hline 70-79 & 1,51 & 1,34 & 1,69 & & 1,49 & 1,41 & 1,57 & \\
\hline$>=79$ & 2,49 & 2,23 & 2,79 & & 2,39 & 2,26 & 2,52 & \\
\hline \multicolumn{9}{|l|}{ Stage at diagnosis } \\
\hline I & 1,00 & & & $<0,001$ & 1,00 & & & $<0,001$ \\
\hline ॥ & 3,20 & 2,35 & 4,36 & & 2,43 & 2,08 & 2,84 & \\
\hline III & 6,49 & 4,81 & 8,76 & & 5,93 & 5,11 & 6,89 & \\
\hline IV & 29,22 & 21,80 & 39,18 & & 23,44 & 20,21 & 27,18 & \\
\hline \multicolumn{9}{|l|}{ Topography } \\
\hline Right colon & 1,00 & & & $<0,001$ & 1,00 & & & $<0,001$ \\
\hline Left Colon & 0,92 & 0,83 & 1,01 & & 0,90 & 0,85 & 0,94 & \\
\hline Recto-sigmoide junction & 0,85 & 0,75 & 0,97 & & 0,85 & 0,80 & 0,91 & \\
\hline Rectum & 1,03 & 0,93 & 1,15 & & 0,87 & 0,83 & 0,91 & \\
\hline \multirow[t]{2}{*}{ Year of diagnosis } & & & & $<0,001$ & & & & $<0,001$ \\
\hline & 0,95 & 0,94 & 0,97 & & 0,97 & 0,97 & 0,98 & \\
\hline \multicolumn{9}{|c|}{ Townsend Deprivation Index } \\
\hline Q1 & 1,00 & & & 0,060 & 1,00 & & & \\
\hline Q2 & 0,84 & 0,73 & 0,98 & & 1,06 & 1,00 & 1,13 & \\
\hline Q3 & 0,88 & 0,76 & 1,02 & & 1,15 & 1,08 & 1,22 & \\
\hline Q4 & 0,92 & 0,81 & 1,05 & & 1,33 & 1,25 & 1,41 & \\
\hline Q5 & 0,97 & 0,85 & 1,09 & & 1,37 & 1,29 & 1,45 & \\
\hline \multicolumn{9}{|c|}{$\begin{array}{l}\text { Travel time no nearest reference } \\
\text { care centre (in } \mathrm{min} \text { ) }\end{array}$} \\
\hline $0-5$ & 1,00 & & & 0,002 & 1,00 & & & 0,075 \\
\hline $5-20$ & 0,87 & 0,70 & 1,08 & & 0,95 & 0,84 & 1,06 & \\
\hline $20-40$ & 1,04 & 0,84 & 1,29 & & 1,00 & 0,89 & 1,13 & \\
\hline $40-90$ & 1,06 & 0,86 & 1,30 & & 1,00 & 0,89 & 1,14 & \\
\hline+90 & 1,05 & 0,83 & 1,32 & & 0,97 & 0,83 & 1,13 & \\
\hline
\end{tabular}


Online S1: Descriptive statistics for travel time to health care for patients diagnosed with colorectal cancer in England and in France between 1997 and 2004 according to deprivation index and stage at diagnosis.

\begin{tabular}{|c|c|c|c|c|c|c|c|c|c|c|c|c|}
\hline \multirow{3}{*}{$\begin{array}{l}\qquad \underline{ } \\
\text { Travel time to nearest } \\
\text { reference cancer centre (in } \\
\text { min) }\end{array}$} & \multicolumn{6}{|c|}{ After imputation } & \multicolumn{6}{|c|}{ Before imputation } \\
\hline & \multicolumn{3}{|c|}{ France } & \multicolumn{3}{|c|}{ England } & \multicolumn{3}{|c|}{ France } & \multicolumn{3}{|c|}{ England } \\
\hline & Mean & & $\% \mathrm{Cl}$ & \multirow[t]{2}{*}{ Mean } & & $\% \mathrm{Cl}$ & \multirow[t]{2}{*}{ Mean } & & $\% \mathrm{Cl}$ & \multirow[t]{2}{*}{ Mean } & & $\% \mathrm{Cl}$ \\
\hline Townsend deprivation Index & & & $<0.001$ & & & $<0.001$ & & & $<0.001$ & & & $<0.001$ \\
\hline Q1 & 45.47 & 43.53 & 47.42 & 35.29 & 34.60 & 35.98 & 45.34 & 43.37 & 47.31 & 34.72 & 33.99 & 35.45 \\
\hline Q2 & 60.30 & 58.23 & 62.36 & 36.17 & 35.48 & 36.86 & 60.40 & 58.22 & 62.57 & 36.21 & 35.45 & 36.98 \\
\hline Q3 & 57.56 & 55.61 & 59.50 & 36.19 & 35.52 & 36.86 & 57.96 & 55.92 & 60.00 & 35.77 & 35.01 & 36.53 \\
\hline Q4 & 50.33 & 48.73 & 51.94 & 33.94 & 33.22 & 34.65 & 50.45 & 48.77 & 52.14 & 33.62 & 32.79 & 34.44 \\
\hline Q5 & 42.00 & 40.72 & 43.28 & 23.51 & 23.00 & 24.03 & 42.19 & 40.84 & 43.55 & 23.44 & 22.84 & 24.05 \\
\hline Dukes' stage at diagnosis & & & 0.261 & & & 0.001 & & & 0.128 & & & 0.881 \\
\hline A & 50.45 & 48.58 & 52.32 & 33.98 & 33.05 & 34.91 & 50.62 & 48.74 & 52.5 & 33.59 & 32.69 & 34.49 \\
\hline B & 49.78 & 48.33 & 51.22 & 33.34 & 32.75 & 33.93 & 49.73 & 48.27 & 51.19 & 33.10 & 32.52 & 33.68 \\
\hline $\mathrm{C}$ & 49.10 & 47.50 & 50.70 & 32.49 & 31.92 & 33.07 & 49.05 & 47.39 & 50.71 & 32.14 & 31.54 & 32.73 \\
\hline $\begin{array}{l}\text { Travel time to nearest } \\
\text { hospital (in } \mathrm{min} \text { ) }\end{array}$ & 49.20 & 47.70 & 50.70 & 32.39 & 31.80 & 32.98 & 49.1 & 47.59 & 50.62 & 32.13 & 31.51 & 32.76 \\
\hline Townsend deprivation Index & & & $<0.001$ & & & $<0.001$ & & & $<0.001$ & & & $<0.001$ \\
\hline Q1 & 15.86 & 15.20 & 16.53 & 16.80 & 16.52 & 17.08 & 15.84 & 15.18 & 16.51 & 16.74 & 16.45 & 17.02 \\
\hline Q2 & 18.87 & 18.12 & 19.62 & 17.26 & 16.96 & 17.56 & 18.85 & 18.09 & 19.62 & 17.26 & 16.93 & 17.60 \\
\hline Q3 & 17.46 & 16.66 & 18.26 & 16.58 & 16.23 & 16.93 & 17.50 & 16.67 & 18.33 & 16.38 & 15.98 & 16.77 \\
\hline Q4 & 14.77 & 14.24 & 15.30 & 14.30 & 14.00 & 14.59 & 14.81 & 14.26 & 15.36 & 14.21 & 13.87 & 14.55 \\
\hline Q5 & 7.63 & 7.27 & 7.99 & 10.52 & 10.36 & 10.67 & 7.54 & 7.17 & 7.92 & 10.49 & 10.32 & 10.65 \\
\hline Dukes' Stage at dia & & & 0.21 & & & 0.009 & & & 0.119 & & & 0.277 \\
\hline$A$ & 14.16 & 13.51 & 14.82 & 15.42 & 15.02 & 15.81 & 14.16 & 13.51 & 14.81 & 15.36 & 14.96 & 15.76 \\
\hline B & 13.93 & 13.42 & 14.45 & 15.08 & 14.83 & 15.33 & 13.91 & 13.40 & 14.43 & 15.00 & 14.75 & 15.26 \\
\hline $\mathrm{C}$ & 13.19 & 12.64 & 13.73 & 15.08 & 14.83 & 15.33 & 13.16 & 12.59 & 13.72 & 15.03 & 14.78 & 15.28 \\
\hline $\begin{array}{l}\text { D } \\
\text { Travel time to radiotherapy } \\
\text { centre (in } \mathrm{min} \text { ) }\end{array}$ & 13.80 & 13.26 & 14.34 & 14.79 & 14.54 & 15.04 & 13.81 & 13.27 & 14.35 & 14.71 & 14.46 & 14.97 \\
\hline Deprivation Index & & & 0.001 & & & $<0.001$ & & & 0.001 & & & $<0.001$ \\
\hline Q1 & 26.81 & 25.61 & 28.00 & 38.04 & 37.57 & 38.51 & 26.66 & 25.47 & 27.85 & 38.24 & 37.72 & 38.75 \\
\hline Q2 & 35.61 & 34.26 & 36.96 & 38.92 & 38.42 & 39.41 & 35.72 & 34.29 & 37.14 & 39.17 & 38.61 & 39.73 \\
\hline Q3 & 36.73 & 35.39 & 38.06 & 38.66 & 38.16 & 39.16 & 36.76 & 35.37 & 38.15 & 38.66 & 38.10 & 39.22 \\
\hline Q4 & 32.83 & 31.75 & 33.91 & 35.43 & 34.95 & 35.90 & 32.74 & 31.62 & 33.85 & 35.33 & 34.80 & 35.86 \\
\hline Q5 & 27.31 & 26.36 & 28.26 & 27.20 & 26.81 & 27.59 & 27.46 & 26.45 & 28.46 & 27.30 & 26.85 & 27.74 \\
\hline Dukes' stage at diagnosis & & & 0.94 & & & $<0.001$ & & & 0.71 & & & 0.00 \\
\hline A & 30.81 & 29.53 & 32.10 & 36.30 & 35.67 & 36.92 & 30.83 & 29.54 & 32.12 & 36.26 & 35.61 & 36.90 \\
\hline B & 31.71 & 30.73 & 32.68 & 35.98 & 35.56 & 36.40 & 31.77 & 30.78 & 32.76 & 35.94 & 35.52 & 36.36 \\
\hline$C$ & 31.08 & 29.97 & 32.18 & 35.35 & 34.94 & 35.77 & 31.00 & 29.88 & 32.11 & 35.28 & 34.85 & 35.71 \\
\hline D & 31.23 & 30.22 & 32.25 & 34.95 & 34.54 & 35.37 & 31.16 & 30.15 & 32.16 & 34.96 & 34.52 & 35.40 \\
\hline
\end{tabular}




\section{Competing interests}

Nonet declared

\section{References}

Baade, P. D., Dasgupta, P., Aitken, J. F., \& Turrell, G. (2011). Distance to the closest radiotherapy facility and survival after a diagnosis of rectal cancer in Queensland. Med J Aust, 195(6), 350354.

Bossard, N., Velten, M., Remontet, L., Belot, A., Maarouf, N., Bouvier, A. M., . . Faivre, J. (2007). Survival of cancer patients in France: A population-based study from the Association of the French Cancer Registries (FRANCIM). European Journal of Cancer, 43(1), 149-160.

Bouche, G., Migeot, V., Mathoulin-Pelissier, S., Salamon, R., \& Ingrand, P. (2008). Breast cancer surgery: Do all patients want to go to high-volume hospitals? Surgery, 143(6), 699-705.

Campbell, N. C., Elliott, A. M., Sharp, L., Ritchie, L. D., Cassidy, J., \& Little, J. (2000). Rural factors and survival from cancer: analysis of Scottish cancer registrations. British Journal of Cancer, 82(11), 1863-1866.

Campbell, N. C., Elliott, A. M., Sharp, L., Ritchie, L. D., Cassidy, J., \& Little, J. (2001). Rural and urban differences in stage at diagnosis of colorectal and lung cancers. British Journal of Cancer, 84(7), 910-914.

Campbell, N. C., Elliott, A. M., Sharp, L., Ritchie, L. D., Cassidy, J., \& Little, J. (2002). Impact of deprivation and rural residence on treatment of colorectal and lung cancer. British Journal of Cancer, 87(6), 585-590.

Coleman, M. P., Rachet, B., Woods, L. M., Mitry, E., Riga, M., Cooper, N., . . Estève, J. (2004). Trends and socioeconomic inequalities in cancer survival in England and Wales up to 2001. Br J Cancer, 90(7), 1367-1373.

Crawford, S. M., Sauerzapf, V., Haynes, R., Zhao, H., Forman, D., \& Jones, A. P. (2009). Social and geographical factors affecting access to treatment of lung cancer. Br J Cancer, 101(6), 897901. doi: 10.1038/sj.bjc.6605257

Danieli, C., Remontet, L., Bossard, N., Roche, L., \& Belot, A. (2012). Estimating net survival: the importance of allowing for informative censoring. Stat Med, 31(8), 775-786. doi: 10.1002/sim.4464

Dejardin, O., Bouvier, A. M., Faivre, J., Boutreux, S., De Pouvourville, G., \& Launoy, G. (2008). Access to care, socioeconomic deprivation and colon cancer survival. Aliment Pharmacol Ther, 27(10), 940-949.

Dejardin, O., Rachet, B., Morris, E., Bouvier, V., Jooste, V., Haynes, R., . . . Launoy, G. (2013). Management of colorectal cancer explains differences in 1-year relative survival between France and England for patients diagnosed 1997-2004. British Journal of Cancer, 108(4), 775783. doi: $10.1038 /$ bjc. 2013.33

Dejardin, O., Remontet, L., Bouvier, A. M., Danzon, A., Tretarre, B., Delafosse, P., . . . Launoy, G. (2006). Socioeconomic and geographic determinants of survival of patients with digestive cancer in France. British Journal of Cancer, 95(7), 944-949.

Dickman, P. W., Sloggett, A., Hills, M., \& Hakulinen, T. (2004). Regression models for relative survival. Stat Med, 23(1), 51-64. doi: 10.1002/sim.1597

Ellis, L., Coleman, M. P., \& Rachet, B. (2012). How many deaths would be avoidable if socioeconomic inequalities in cancer survival in England were eliminated? A national population-based study, 1996-2006. Eur J Cancer, 48(2), 270-278. doi: S0959-8049(11)00795-7 [pii]

10.1016/j.ejca.2011.10.008 
Fritz, A., Percy, C., Jack, A., Shanmugaratnam, K., Sobin, L., Parkin, D. m., \& Whelan, S. (2000). International Classification of diseases for Oncology - Third Edition. Geneva: World Health Organization.

Grafféo, N., Jooste, V., \& Giorgi, R. (2012). The impact of additional life-table variables on excess mortality estimates. Stat Med, 31(30), 4219-4230. doi: 10.1002/sim.5493

Haynes, R., Pearce, J., \& Barnett, R. (2008). Cancer survival in New Zealand: Ethnic, social and geographical inequalities. Soc Sci Med.

Henry, K. A., Niu, X. L., \& Boscoe, F. P. (2009). Geographic disparities in colorectal cancer survival. International Journal of Health Geographics, 8, 13. doi: 10.1186/1476-072x-8-48

Henry, K. A., Sherman, R., Farber, S., Cockburn, M., Goldberg, D. W., \& Stroup, A. M. (2013). The joint effects of census tract poverty and geographic access on late-stage breast cancer diagnosis in 10 US States. Health \& Place, 21, 110-121. doi: 10.1016/j.healthplace.2013.01.007

Huang, B., Dignan, M., Han, D., \& Johnson, O. (2009). Does distance matter? Distance to mammography facilities and stage at diagnosis of breast cancer in Kentucky. J Rural Health, 25(4), 366-371. doi: 10.1111/j.1748-0361.2009.00245.x

Huang, L., Pickle, L. W., Stinchcomb, D., \& Feuer, E. J. (2007). Detection of spatial clusters: application to cancer survival as a continuous outcome. Epidemiology, 18(1), 73-87. doi: 10.1097/01.ede.0000249994.30736.24

Jones, A. P., Haynes, R., Sauerzapf, V., Crawford, S. M., \& Forman, D. (2010). Geographical access to healthcare in Northern England and post-mortem diagnosis of cancer. J Public Health (Oxf), 32(4), 532-537. doi: 10.1093/pubmed/fdq017

Jones, A. P., Haynes, R., Sauerzapf, V., Crawford, S. M., Zhao, H., \& Forman, D. (2008a). Travel time to hospital and treatment for breast, colon, rectum, lung, ovary and prostate cancer. Eur $J$ Cancer.

Jones, A. P., Haynes, R., Sauerzapf, V., Crawford, S. M., Zhao, H., \& Forman, D. (2008b). Travel times to health care and survival from cancers in Northern England. Eur J Cancer, 44(2), 269-274.

Koka, V. K., Potti, A., Fraiman, G. N., Hanekom, D., \& Hanley, J. F. (2002). An epidemiological study evaluating the relationship of distance from a tertiary care cancer center to early detection of colorectal carcinoma. Anticancer Res, 22(4), 2481-2483.

Krieger, N. (1992). Overcoming the absence of socioeconomic data in medical records: validation and application of a census-based methodology. Am J Public Health, 82(5), 703-710.

Launoy, G., Le Coutour, X., Gignoux, M., Pottier, D., \& Dugleux, G. (1992). Influence of rural environment on diagnosis, treatment, and prognosis of colorectal cancer. J Epidemiol Community Health, 46(4), 365-367.

Little, R., \& Rubin, D. (2002). Statistical analysis with missing data. Hoboken, New Jersey: John Wiley \& Sons, Inc.

Mackenbach, J. P., Bakker, M. J., \& European Network Interventions, P. (2003). Tackling socioeconomic inequalities in health: analysis of European experiences. Lancet, 362(9393), 1409-1414.

Meilleur, A., Subramanian, S. V., Plascak, J. J., Fisher, J. L., Paskett, E. D., \& Lamont, E. B. (2013). Rural Residence and Cancer Outcomes in the United States: Issues and Challenges. Cancer Epidemiology Biomarkers \& Prevention, 22(10), 1657-1667. doi: 10.1158/1055-9965.epi-130404

Nur, U., Shack, L. G., Rachet, B., Carpenter, J. R., \& Coleman, M. P. (2010). Modelling relative survival in the presence of incomplete data: a tutorial. Int J Epidemiol, 39(1), 118-128. doi: dyp309 [pii]

10.1093/ije/dyp309

Royston, P. (2009). Multiple imputation of missing values: Further update of ice, with an emphasis on categorical variables. STATA Journal, 9(2), 11.

Rubin, D. (1987). Multiple Imputation for Nonresponse in Surveys. New-York: John Wiley \& Sons. 
Sterne, J. A., White, I. R., Carlin, J. B., Spratt, M., Royston, P., Kenward, M. G., . . Carpenter, J. R. (2009). Multiple imputation for missing data in epidemiological and clinical research: potential and pitfalls. BMJ, 338, b2393.

Verdecchia, A., Francisci, S., Brenner, H., Gatta, G., Micheli, A., Mangone, L., \& Kunkler, I. (2007). Recent cancer survival in Europe: a 2000-02 period analysis of EUROCARE-4 data. Lancet Oncol, 8(9), 784-796.

Woods, L. M., Rachet, B., \& Coleman, M. P. (2006). Origins of socio-economic inequalities in cancer survival: a review. Ann Oncol, 17(1), 5-19. 